\title{
Thermal-hydraulic analysis of the coil test facility for CFETR
}

\author{
Yong Ren*', Xiaogang Liu, Junjun Li, Zhaoliang Wang, Lilong Qiu, Shijun Du, Guoqiang Li and Xiang Gao
}

\author{
${ }^{*}$ Correspondence: renyong@ \\ mail.ustc.edu.cn \\ Institute of Plasma Physics, \\ Hefei Institutes of Physical \\ Science, Chinese Academy \\ of Sciences, PO Box 1126, \\ Hefei 230031, Anhui, People's \\ Republic of China
}

\begin{abstract}
Background: Performance test of the China Fusion Engineering Test Reactor (CFETR) central solenoid (CS) and toroidal field (TF) insert coils is of great importance to evaluate the CFETR magnet performance in relevant operation conditions. The superconducting magnet of the coil test facility for CFETR is being designed with the aim of providing a background magnetic field to test the CFETR CS insert and TF insert coils.
\end{abstract}

Results: The superconducting magnet consists of the inner module with $\mathrm{Nb}_{3} \mathrm{Sn}$ coil and the outer module with NbTi coil. The superconducting magnet is designed to have a maximum magnetic field of $12.59 \mathrm{~T}$ and a stored energy of $436.6 \mathrm{MJ}$. An active quench protection circuit and the positive temperature coefficient dump resistor were adopted to transfer the stored magnetic energy.

Conclusions: The temperature margin behavior of the test facility for CFETR satisfies the design criteria. The quench analysis of the test facility shows that the cable temperature and the helium pressure inside the jacket are within the design criteria.

Keywords: Cable-in-conduit conductor (CICC), CFETR, Quench, Superconducting magnet, Thermal-hydraulic behavior

\section{Background}

PERFORMACNE test of the China Fusion Engineering Test Reactor (CFETR) central solenoid (CS) and toroidal field (TF) insert coils is of great importance to evaluate the CFETR magnet performance in relevant operation conditions (Ren et al. 2015a). A superconducting magnet of the coil test facility for CFETR magnet is being designed. The superconducting magnet consists of two parts, i.e. the inner part with $\mathrm{Nb}_{3} \mathrm{Sn}$ coil and the outer part with NbTi coil. Both coils are designed based on the Cable-In-Conduit Conductor (CICC) technology. The superconducting magnet has a stored energy of $436.6 \mathrm{MJ}$ and a maximum magnetic field of $12.59 \mathrm{~T}$. The superconducting magnet will be cooled with supercritical helium at $4.5 \mathrm{~K}$ inlet temperature. During the operation, the AC losses due to changing magnetic fields and the heat leak from the environment will increase the operating temperature and minimize the temperature margin (Ren et al. 2012). Therefore, the temperature margin behavior of the superconducting magnet needs to be analyzed in relevant operating conditions. Once the operating temperature exceeds the current sharing temperature, a large hot spot temperature in the normal zone region can be developed. It is very important to make every effort to avoid quench of the superconducting magnet from the electromagnetic and heat disturbance. 
However, the appropriate quench design is mandatory to avoid the severe failure due to the overheating of the cable and the overstressing of the jacket during a quench (Wang et al. 2004; Meuris et al. 2010; Takahashi et al. 2006). In addition, the appropriate quench protection circuit is required to distinguish between quench signal and noise (Gaio et al. 2013; Takahashi et al. 2005; Martovetsky and Radovinsky 2006; Lacroix et al. 2013). The parametric analysis on the hot spot temperature and helium pressure behavior is required to understand the influence of the initial some initial thermal-hydraulic parameters for the quench analysis (Nicollet et al. 2013).

To reduce the quench voltage of the coil terminals and to accelerate the current decay during a quench, the ST-08 stainless steel with positive temperature coefficient will be adopted as the material of dump resistor (Ren et al. 2015b). The 1-D GANDALF code was used to analyze the temperature margin and quench propagation behavior (Bottura 1996).

In this paper, the temperature margin behavior and the quench propagation behavior of the superconducting magnet are described.

\section{Results}

\section{Description of the superconducting magnet}

The superconducting magnet consists of the inner module with $\mathrm{Nb}_{3} \mathrm{Sn}$ coil and the outer module with $\mathrm{NbTi}$ coil. The $\mathrm{Nb}_{3} \mathrm{Sn}$ cable is made of $864 \mathrm{Nb}_{3} \mathrm{Sn}$ and 432 copper strands inserted into a round-in-square modified 316LN stainless steel jacket with low carbon content to form a CICC conductor. The NbTi cable is made of $1440 \mathrm{NbTi}$ strands inserted into a round-in-square $316 \mathrm{~L}$ stainless steel jacket to form a CICC conductor. $\mathrm{The} \mathrm{Nb}_{3} \mathrm{Sn}$ coil, which is layer-wound winding, has eight layers with eight cooling channels. The NbTi coils are pancake wound to minimize the length of the cooling channel. There are ten cooling channels for NbTi coils; each cooling channel has two pancakes. Table 1 lists the design parameters of the superconducting magnet. Figure 1 shows the cross section of a winding pack of the superconducting magnet. Figure 2 shows the magnetic field distribution of the superconducting magnet.

\section{Table 1 Design parameters of the superconducting magnet}

\begin{tabular}{lll}
\hline Superconductor & $\mathbf{N b}_{\mathbf{3}} \mathbf{S n}$ & $\mathbf{N b T i}$ \\
\hline Jacket & $316 \mathrm{LN}$ & $316 \mathrm{~L}$ \\
Inner diameter $(\mathrm{mm})$ & 1.4000 & 2.3808 \\
Outer diameter $(\mathrm{mm})$ & 2.3608 & 3.5288 \\
Height $(\mathrm{mm})$ & 1.7050 & 1.1510 \\
Turn insulation $(\mathrm{mm})$ & 1.0 & 1.0 \\
Layer/pancake insulation $(\mathrm{mm})$ & 2.0 & 1.0 \\
Layer/Pancake & 8 & 20 \\
Turns per layer or pancake & 30 & 10 \\
Void fraction in the ClCC & 0.3 & 0.34 \\
Current (kA) & 56 & \\
Inductance $(\mathrm{H})$ & 0.2784 & \\
Stored energy $(\mathrm{MJ})$ & 436.6 & 5.455 \\
Maximum field $(\mathrm{T})$ & 12.59 &
\end{tabular}



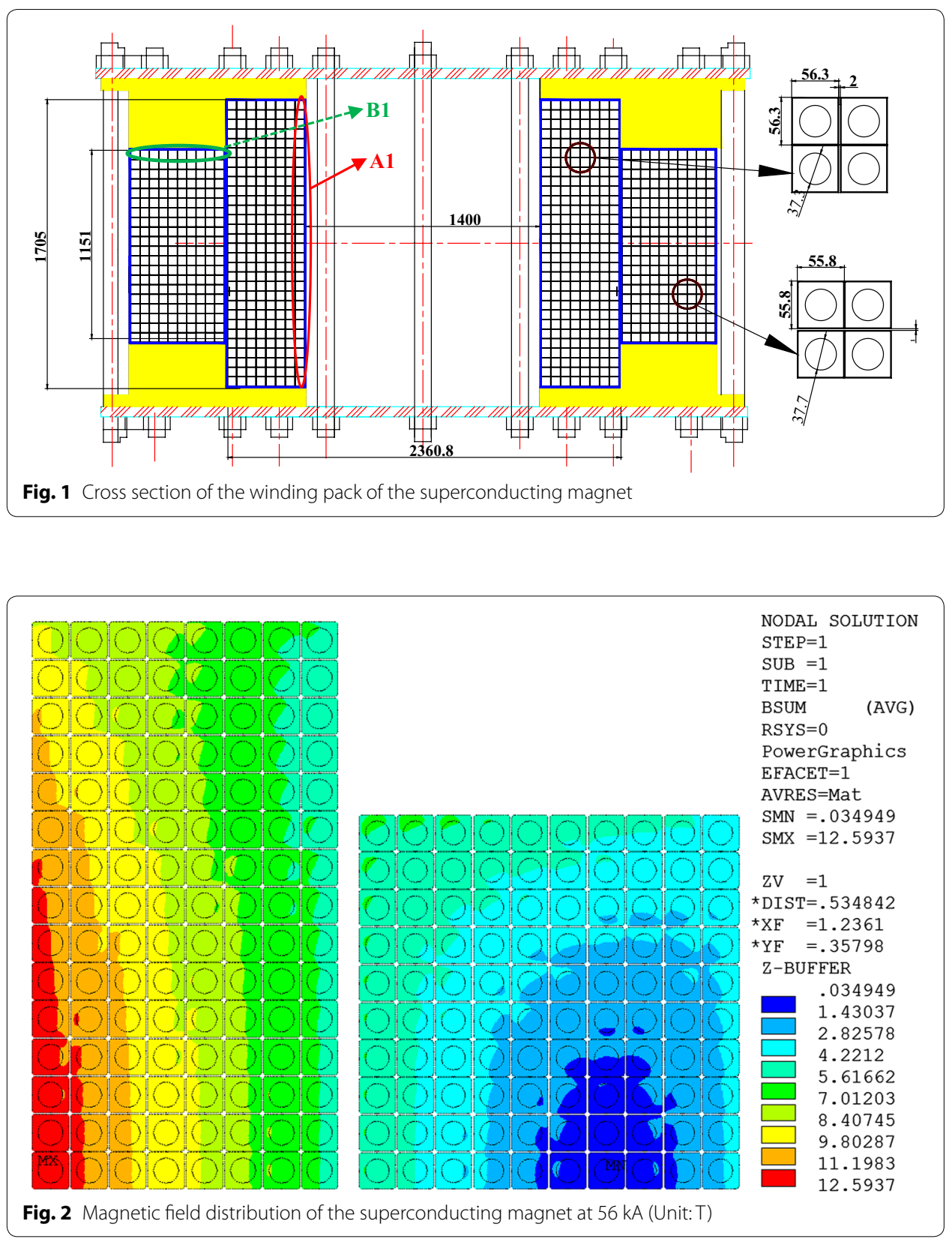

The $\mathrm{Nb}_{3} \mathrm{Sn}$ CICC conductors are cooled with the forced flow supercritical helium at $0.55 \mathrm{MPa}$ pressure, $12 \mathrm{~g} / \mathrm{s}$ mass flow rate and $4.5 \mathrm{~K}$ temperature at the coil inlet. The $\mathrm{NbTi}$ coils are cooled with supercritical helium at inlet pressure of $0.55 \mathrm{MPa}$, mass flow rate of $8 \mathrm{~g} / \mathrm{s}$ and $4.5 \mathrm{~K}$ temperature at the inlet. The hydraulic parameters of the $\mathrm{Nb}_{3} \mathrm{Sn}$ and NbTi CICCs for the superconducting magnet can be shown in references (Ren et al. 2015a; ITER 2009).

The scaling law and the scaling parameters of the $\mathrm{Nb}_{3} \mathrm{Sn}$ superconductor can be shown in Ref. (ITER 2009; Godeke et al. 2006). The effective filament diameter is $30 \mu \mathrm{m}$ for the $\mathrm{Nb}_{3} \mathrm{Sn}$ strand (Bottura 2000). The longitudinal strain of the $\mathrm{Nb}_{3} \mathrm{Sn}$ strand is mainly composed of the thermal strain from the thermal contraction and the strain from the 
magnetic loading. The thermal strain of the $\mathrm{Nb}_{3} \mathrm{Sn}$ strand in a CICC with $316 \mathrm{LN}$ stainless steel jacket was assumed as $-0.664 \%$ (ITER 2009). The cables in the CICCs are assumed to be fully bonded to the inner surface of the jacket for the mechanical behavior analysis. The 316LN stainless steel jacket with isotropic material properties and the insulation material with orthotropic material properties are used for the mechanical behavior analysis, which can be described in Ref. (Jong and al 2009). The effective material properties in the cable regions, which consists of Young's modulus, shear modulus, thermal contraction and Poisson ratio, can be obtained with the finite element methods based on the homogeneous theory (Kaminski and Schrefler 2000). A linear elastic analysis using the relevant stress-strain model is performed to analyze the strain of the cable. The strain generated by the magnetic force is shown in Fig. 3. The critical current density of the NbTi superconductor can be obtained by using the single pinning model (Bottura 2000). The scaling law and the scaling parameters of the critical current density in NbTi superconductor can be shown in relevant expressions (Bottura 2000; Zani et al. 2005). The effective filament diameter is about $8 \mu \mathrm{m}$ for the NbTi strand. It is hard to accurately evaluate the coupling time constant of the CICC conductors. The coupling time constants of the CICC conductors are usually dependent on the local magnetic forces, the load cycle process, void fraction, cable layout, aspect ratio, coating material of the cable, and the magnet ramp rate, etc. (Bruzzone et al. 2006; Bruzzone et al. 2009; Hamada et al. 2004; Ilyin et al. 2010; Cau and Bruzzone 2010; Cau et al. 2009). For simplicity, the coupling time constants with nt values of the $\mathrm{Nb}_{3} \mathrm{Sn}$ and $\mathrm{NbTi}$ CICC conductors were selected as 0.075 and $0.15 \mathrm{~s}$ for evaluating AC losses respectively (ITER 2009). The pressure drop in the central channel and the bundle for the CICC using the relevant expressions can be described in (1-3) (Cau et al. 2009; Hamada et al. 2002; Nicollet and al 2014).

$$
\begin{aligned}
& \frac{d p}{d x}=-2 \rho \frac{f}{D_{h}} v|v| \\
& f_{\text {bundle }}=\frac{1}{4 v_{f}^{0.742}}\left(\frac{19.5}{\operatorname{Re}^{0.7953}}+0.0231\right) \\
& f_{\text {central }}=0.36 \times \frac{1}{\operatorname{Re}^{0.04}} \times 0.25
\end{aligned}
$$

where $d p / d x$ is the pressure gradient, $f$ is the friction factor, $f_{\text {bundle }}$ and $f_{\text {central }}$ are friction factors of the bundle and the central channel, $\rho$ is the density of the helium, $v$ is the flow speed, $v_{f}$ is the void fraction, Re is the Reynolds number, $D_{\mathrm{h}}$ is the hydraulic diameter.

\section{Thermal-hydraulic analysis of the superconducting magnet}

\section{Current sharing temperature of the superconducting magnet}

The maximum magnetic field is located at the innermost layer for the $\mathrm{Nb}_{3} \mathrm{Sn}$ coil. The temperature margin and quench propagation behavior of the innermost layer of the $\mathrm{Nb}_{3} \mathrm{Sn}$ coil were analyzed. For the NbTi coils, the temperature and quench behavior of the top channel was analyzed due to the lowest value of the minimum temperature 


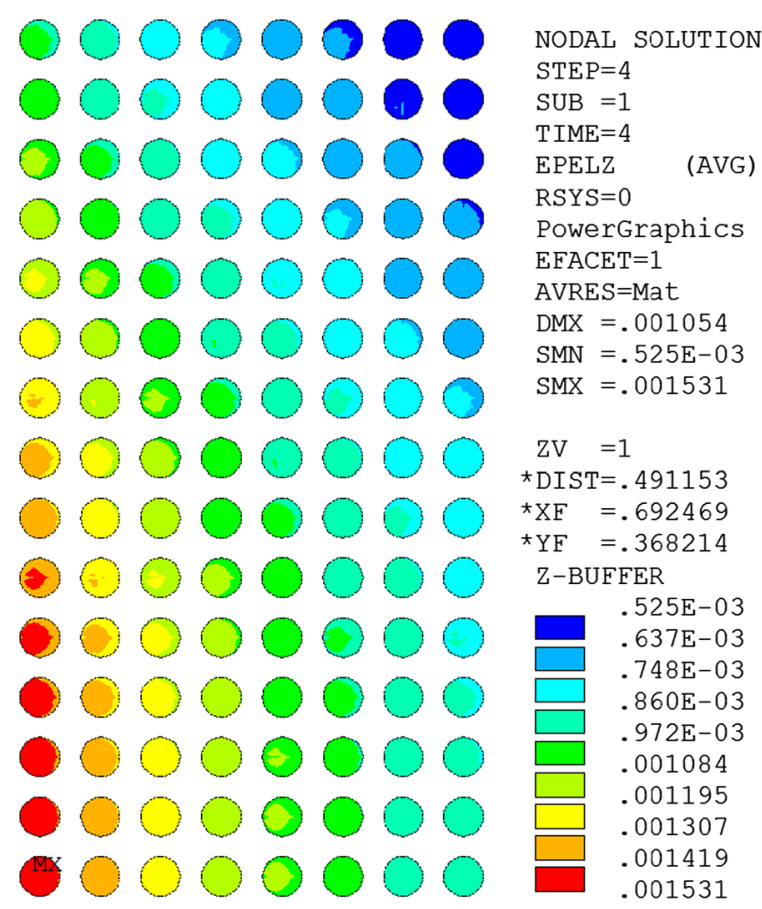

Fig. 3 Hoop strain distribution of the superconducting cables at $56 \mathrm{kA}$

margin is located at the top and bottom channels symmetrically. Here, we refer the innermost layer of the $\mathrm{Nb}_{3} \mathrm{Sn}$ coil and the top channel of the NbTi coil as A1 and B1 channels, as shown in Fig. 1. Figure 4 shows the current sharing temperature of the A1 channel and the B1 channel when the operating current reaches the rated current. The minimum current sharing temperature are about 6.3 and $6.4 \mathrm{~K}$ for both channels.

The superconducting magnet has a chance to operate in a cyclic operation to evaluate the conductor performance. Here, we selected a typical cyclic operation mode when the magnet is linearly ramped up to the rated field and then ramped down to zero field, cycle after cycle. The ramp rate of $280 \mathrm{~A} / \mathrm{s}$ was firstly assumed in this case. Figures 5 and 6 show the maximum cable temperature, outlet temperature and minimum temperature margin evolution as functions of time for both channels. The analysis results are shown that the lowest values of the minimum temperature margin for the A1 and B1 channels are 1.50 and 1.70 respectively.

A parametric analysis was performed to evaluate the minimum temperature margin sensitivity to the current ramp rate for both channels. Figure 7 shows the minimum temperature margin as a function of the ramp rate for cyclic operation. It is shown that the continuous cyclic operations can be allowed for the current ramp rate below 280 $\mathrm{A} / \mathrm{s}$. With increasing the current ramp rate, the minimum temperature margin will drop below $1.0 \mathrm{~K}$ for the current ramp rate of $500 \mathrm{~A} / \mathrm{s}$.

\section{Quench analysis of the superconducting magnet}

The superconducting magnet will store a large magnetic energy of about $436.6 \mathrm{MJ}$ at 56 $\mathrm{kA}$. To avoid the overheating from the hot spot temperature, an appropriate quench protection is required. The quench protection circuit is composed of the DC power supply, 


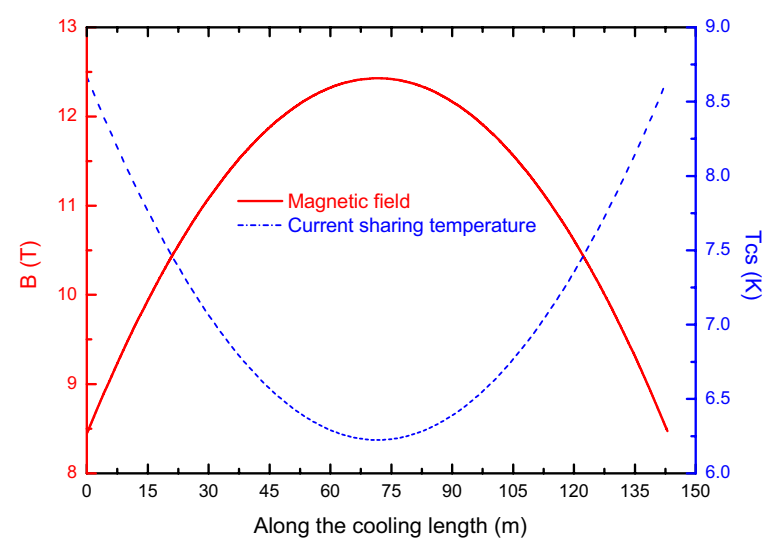

a

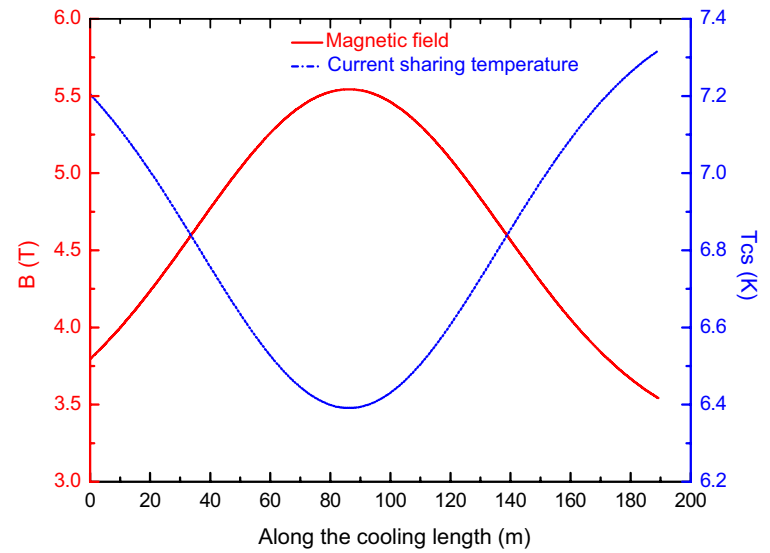

b

Fig. 4 Magnetic field and current sharing temperature at $56 \mathrm{kA}$ along the cooling length of a the A1 channel and $\mathbf{b}$ the B1 channel

quench detection circuit, coil isolation amplifiers, dump resistor, diode stack, breaker control system, switch control system and emergency dump breakers etc. The quench detection circuit will be used to monitor the voltage of the superconducting magnet. The high speed DC circuit breakers are used to protect the superconducting coils in case of a quench. The input power will be interrupted by opening the emergency dump circuit breakers.

The quench propagation behavior was analyzed with the $1 \mathrm{D}$ Gandalf code, together with the adiabatic hot spot temperature criterion. The allowable maximum hot spot temperature is about $150 \mathrm{~K}$ with the 1-D Gandalf code. The allowable maximum hot spot temperature is about $250 \mathrm{~K}$ by considering only the heat capacity of the cable for the adiabatic hot spot temperature criterion. The initial quench triggering point can be taken place in $\mathrm{Nb}_{3} \mathrm{Sn}$ coil or $\mathrm{NbTi}$ coil. So, the quench propagation behavior of the A1 channel and B1 channel needs to be analyzed.

The normal zone length and quench voltage can be obtained with the 1 D GANDALF code. To trigger a quench, a rectangular heat input $(1 \mathrm{~m}, 0.1 \mathrm{~s})$ was exerted into the cable to drive the cable into the normal state. The triggered energy adopted is about 

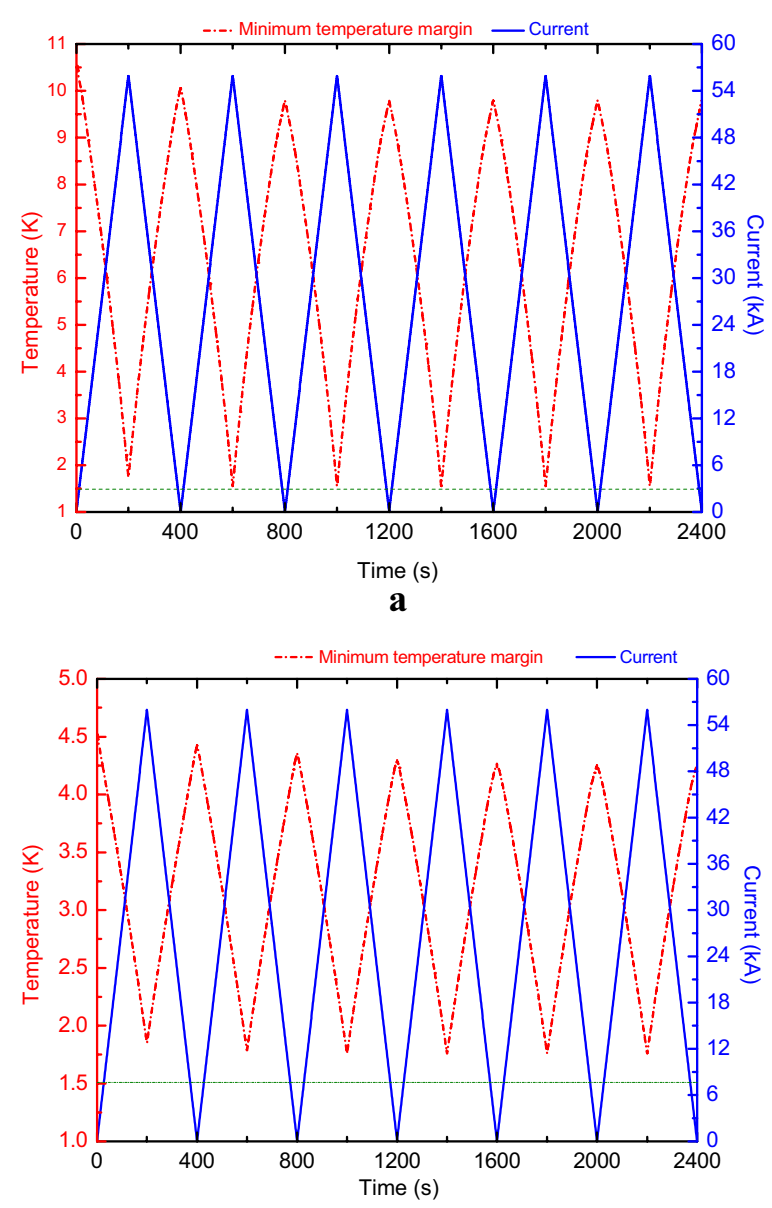

b

Fig. 5 Minimum temperature margin and current evolution as functions of time for $\mathbf{a}$ the A1 channel and b the B1 channel

2 times the energy needed to cause an irreversible quench. Figure 8 shows the normal zone length and quench voltage as functions of time for the $\mathrm{A} 1$ and $\mathrm{B} 1$ channels. It takes about $1.80 \mathrm{~s}$ to reach the quench voltage of $0.4 \mathrm{~V}$ for the A1 channel. It takes about $2.78 \mathrm{~s}$ to reach the quench voltage of $0.4 \mathrm{~V}$ for the B1 channel. To open the circuit breaker, it will take about $0.5 \mathrm{~s}$. As a first step, the adiabatic hot spot temperature criteria, together with the quench voltage behavior calculated by the 1 D GANDALF code was adopted to obtain the maximum holding time. The holding time represents the period between quench detection and breaker opening. The total equivalent thermal time constant of the A1 channel and B1 channel are about 9.8 and 8.2 s respectively.

The discharge time constant is selected as $2.8 \mathrm{~s}$ for the superconducting magnet. The maximum holding time can be obtained as $6.1 \mathrm{~s}$ by taking into account the threshold voltage of $0.4 \mathrm{~V}$ if the quench originated from the $\mathrm{A} 1$ channel. The maximum holding time can be obtained as $3.52 \mathrm{~s}$ by taking into account the threshold voltage of $0.4 \mathrm{~V}$ and the discharge time constant of $2.8 \mathrm{~s}$ if the quench originated from the B1 channel. As shown in Ref. (Martovetsky et al. 2016), the cable temperature differs from the jacket temperature as a result of the quench propagation with delay. Therefore, a relatively less 
Rene et al. SpringerPlus (2016) 5:2052

Page 8 of 13
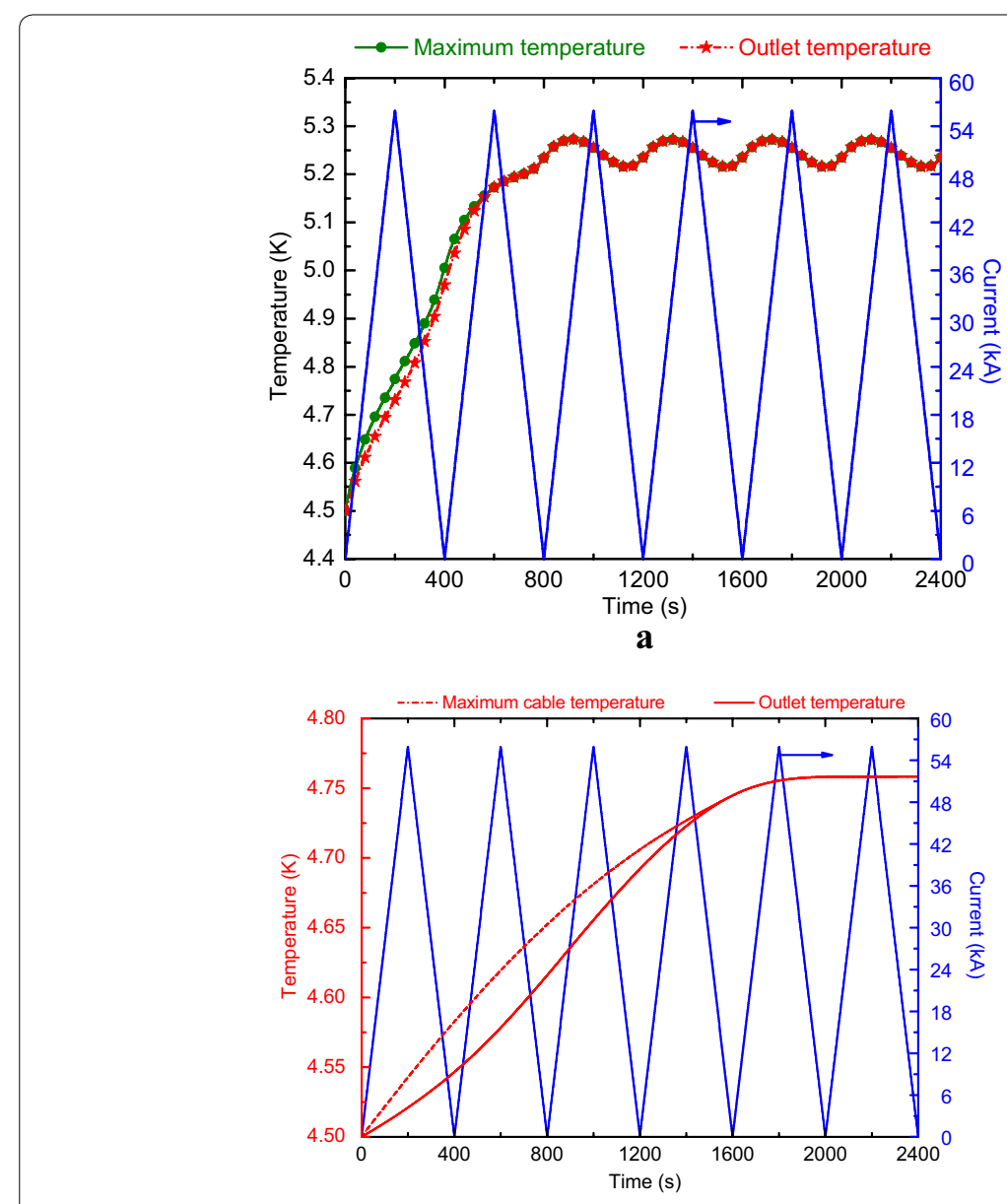

b

Fig. 6 Maximum temperature, outlet temperature and current evolution as functions of time for $\mathbf{a}$ the A1 channel and $\mathbf{b}$ the B1 channel

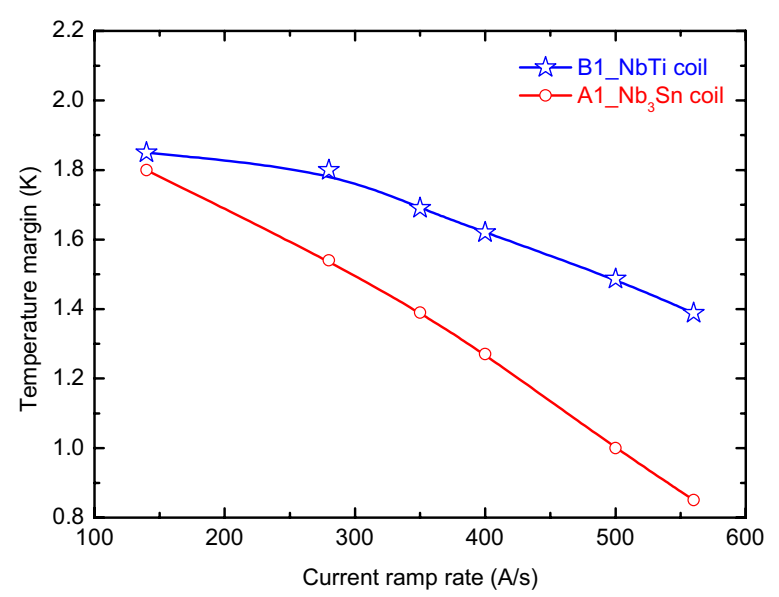

Fig. 7 The lowest value of the minimum temperature margin vs current ramp rate for cyclic operation 


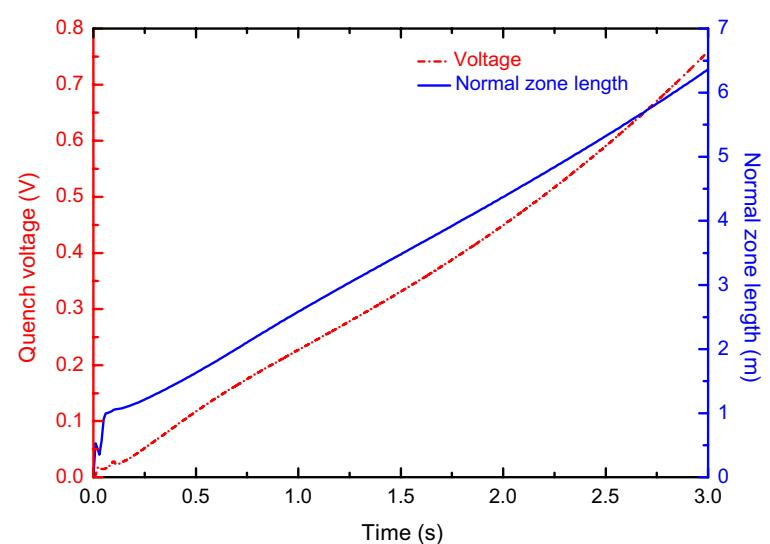

a

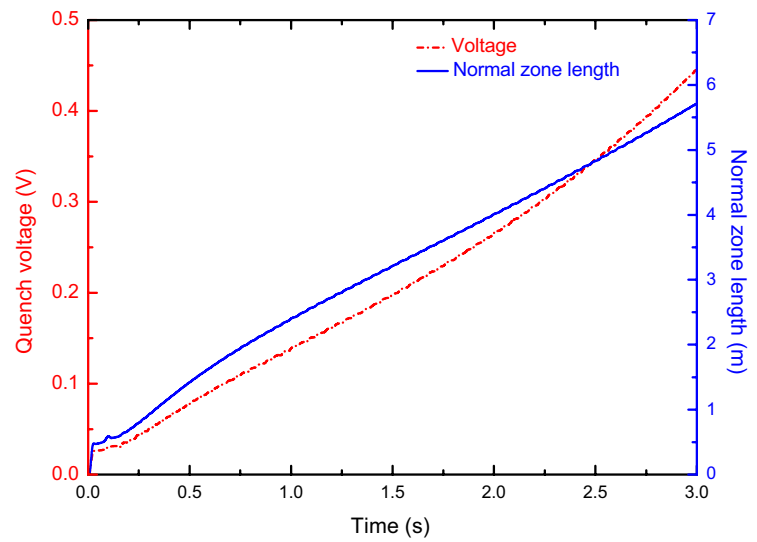

b

Fig. 8 Normal zone length and quench voltage evolution as functions of time for $\mathbf{a}$ the A1 channel and b the B1 channel

holding time was selected for limiting the hot spot temperature of the cable. The threshold voltage and holding time can be designed as $0.4 \mathrm{~V}$ and $2.0 \mathrm{~s}$ respectively.

Figure 9 shows the cable temperature and helium pressure evolution along the cooling length of the A1 channel as functions of time with the holding time of $2.0 \mathrm{~s}$, initial disturbance length of $1 \mathrm{~m}$ and quench threshold voltage of $0.4 \mathrm{~V}$. The maximum cable temperature is about $78.9 \mathrm{~K}$, which is well below the ITER design criterion. The maximum helium pressure inside the $316 \mathrm{LN}$ jacket is about $4.2 \mathrm{MPa}$, which is well below the ITER design criterion of $25 \mathrm{MPa}$.

Figure 10 shows the evolution of the cable temperature and helium pressure inside the jacket of the B1 channel along the cooling length for different times with the holding time of $2.0 \mathrm{~s}$, initial disturbance length of $1 \mathrm{~m}$ and quench threshold voltage of $0.4 \mathrm{~V}$. It is shown that the maximum cable temperature of the NbTi cable is about $76.7 \mathrm{~K}$, which is well below the ITER design criterion. The maximum helium pressure inside the $316 \mathrm{~L}$ jacket is about $1.66 \mathrm{MPa}$, which is well below the ITER design criterion of $25 \mathrm{MPa}$.

To evaluate the sensitivity of the maximum cable temperature and maximum helium pressure inside the jacket to the holding time, the initial disturbance length, and the threshold voltage, the parametric analysis was performed for both channels. The analysis 


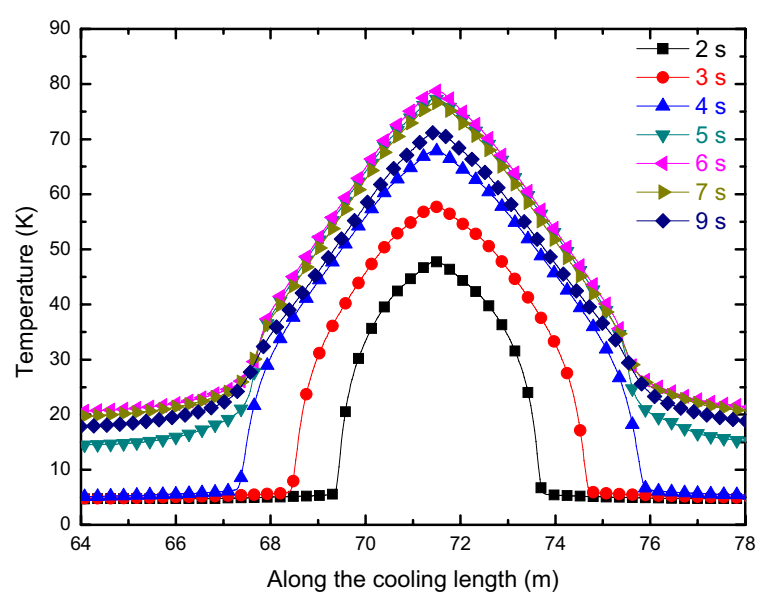

a

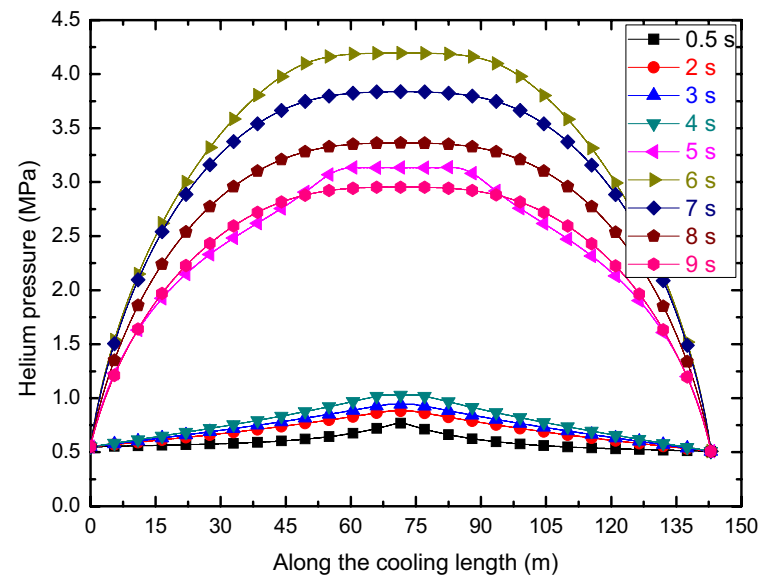

b

Fig. 9 Cable temperature (a) and Helium pressure (b) evolution along the cooling length as functions of time for the A1 channel

results are shown in Tables 2, 3 and 4. The maximum cable temperature increases with increasing the holding time and threshold voltage for both channels. The disturbance length has the opposite effects on the maximum cable temperature. The threshold voltage and the holding time have a negligible impact on the maximum helium pressure while the initial disturbance length has a substantial impact on the maximum helium pressure. The maximum helium pressure is about 7.22 MPa for the threshold voltage of $0.4 \mathrm{~V}$, the holding time of $2.0 \mathrm{~s}$ and the disturbance length of $10.0 \mathrm{~m}$ for the $\mathrm{A} 1$ channel. The maximum cable temperature is about $106.4 \mathrm{~K}$ for the threshold voltage of $0.4 \mathrm{~V}$, the holding time of $4.0 \mathrm{~s}$ and the disturbance length of $1.0 \mathrm{~m}$ for the A1 channel. The maximum cable temperature is about $111.1 \mathrm{~K}$ for the threshold voltage of $0.4 \mathrm{~V}$, the holding time of $4.0 \mathrm{~s}$ and the disturbance length of $1.0 \mathrm{~m}$ for the B1 channel. Therefore, the superconducting magnet can be protected with the threshold voltage of $0.4 \mathrm{~V}$ and holding time of $2.0 \mathrm{~s}$. 


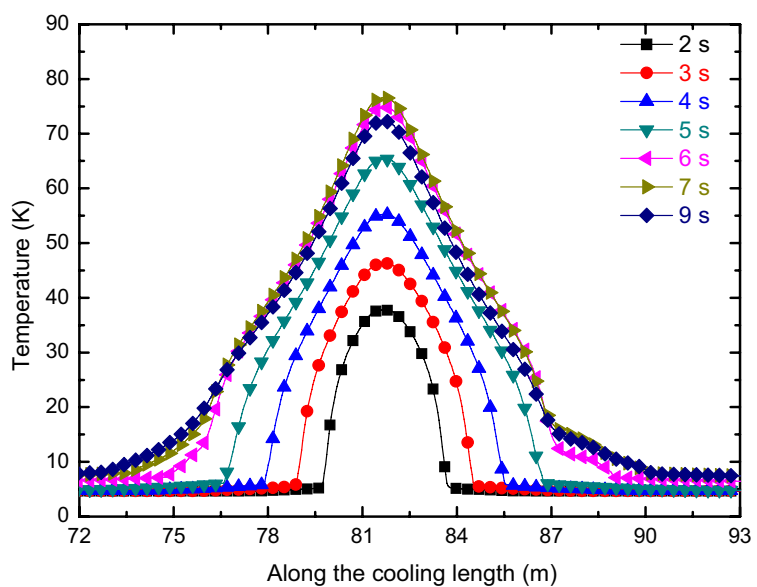

a

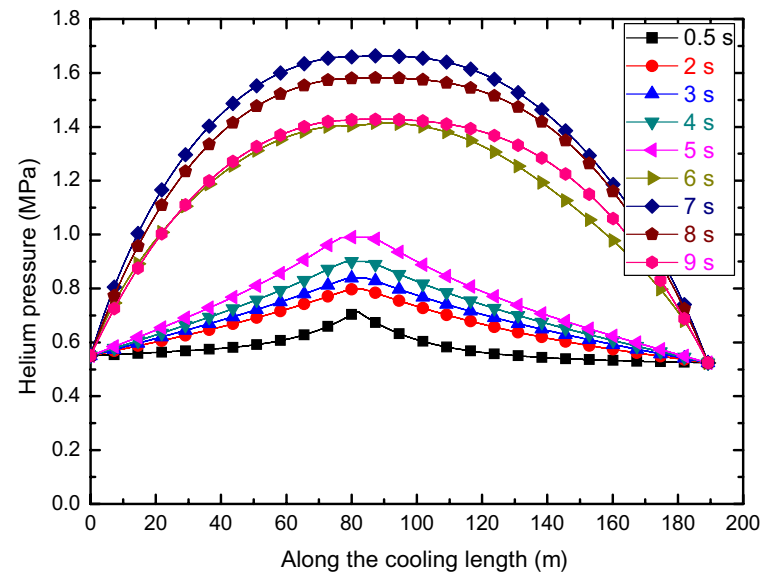

b

Fig. 10 Cable temperature (a) and Helium pressure (b) evolution along the cooling length as functions of time for the B1 channel

Table 2 Sensitivity of maximum cable temperature and maximum helium pressure to disturbance length for the A1 and B1 channels

\begin{tabular}{|c|c|c|c|c|}
\hline \multirow{2}{*}{$\begin{array}{l}\text { Disturbance length } \\
\text { (m) }\end{array}$} & \multicolumn{2}{|l|}{ A1 channel } & \multicolumn{2}{|l|}{ B1 channel } \\
\hline & $\begin{array}{l}\text { Max. cable tem- } \\
\text { perature }(\mathrm{K})\end{array}$ & $\begin{array}{l}\text { Max. helium pres- } \\
\text { sure }(\mathrm{MPa})\end{array}$ & $\begin{array}{l}\text { Max. cable tem- } \\
\text { perature }(\mathrm{K})\end{array}$ & $\begin{array}{l}\text { Max. helium } \\
\text { pressure (MPa) }\end{array}$ \\
\hline 0.5 & 84.0 & 4.17 & 82.8 & 1.63 \\
\hline 1.0 (Ref.) & 78.9 & 4.18 & 76.6 & 1.66 \\
\hline 10.0 & 58.0 & 7.22 & 50.3 & 2.93 \\
\hline
\end{tabular}

\section{Conclusion}

The temperature margin behavior and quench propagation behavior of the superconducting magnet are analyzed. The analysis results show that the magnet has the sufficient minimum temperature margin. The quench analysis is shown that the hot spot temperature and the helium pressure inside the jacket are well below the ITER design 
Table 3 Sensitivity of maximum cable temperature and maximum helium pressure to threshold voltage for the A1 and B1 channels

\begin{tabular}{|c|c|c|c|c|}
\hline \multirow{2}{*}{$\begin{array}{l}\text { Threshold voltage } \\
\text { (V) }\end{array}$} & \multicolumn{2}{|l|}{ A1 channel } & \multicolumn{2}{|l|}{ B1 channel } \\
\hline & $\begin{array}{l}\text { Max. cable tem- } \\
\text { perature }(\mathrm{K})\end{array}$ & $\begin{array}{l}\text { Max. helium pres- } \\
\text { sure }(\mathrm{MPa})\end{array}$ & $\begin{array}{l}\text { Max. cable tem- } \\
\text { perature }(\mathrm{K})\end{array}$ & $\begin{array}{l}\text { Max. helium } \\
\text { pressure (MPa) }\end{array}$ \\
\hline 0.3 & 74.3 & 4.18 & 68.3 & 1.65 \\
\hline 0.4 (Ref.) & 78.9 & 4.19 & 76.6 & 1.66 \\
\hline 0.45 & 81.3 & 4.22 & 82.3 & 1.68 \\
\hline 0.50 & 83.8 & 4.24 & 82.4 & 1.69 \\
\hline
\end{tabular}

Table 4 Sensitivity of maximum cable temperature and maximum helium pressure to holding time for the $A 1$ and $B 1$ channels

\begin{tabular}{llllll}
\hline Holding time (s) & A1 channel & & \multicolumn{3}{l}{ B1 channel } \\
\cline { 2 - 3 } & $\begin{array}{l}\text { Max. cable tempera- } \\
\text { ture (K) }\end{array}$ & $\begin{array}{l}\text { Max. helium pres- } \\
\text { sure (MPa) }\end{array}$ & & $\begin{array}{l}\text { Max. cable tempera- } \\
\text { ture (K) }\end{array}$ & $\begin{array}{l}\text { Max. helium } \\
\text { pressure (MPa) }\end{array}$ \\
\hline 2.0 (Ref.) & 78.9 & 4.18 & & 76.6 & 1.66 \\
2.5 & 85.0 & 4.19 & 83.9 & 1.70 \\
3.0 & 91.6 & 4.22 & 92.0 & 1.75 \\
3.5 & 98.7 & 4.24 & 101.0 & 1.81 \\
4.0 & 106.4 & 4.27 & 111.1 & 1.90 \\
\hline
\end{tabular}

criteria. Therefore, the quench protection parameters selected can be designed to safely protect the superconducting magnet.

Authors' contributions

YR and XL carried out the design and analysis of the superconducting magnet. YR, JJL, ZLW, LLQ, SJD, GQL and XG helped to draft the manuscript. All authors read and approved the final manuscript.

\section{Acknowledgements}

This work was supported in part by the National Natural Science Foundation of China under (Grant No. 51406215, some 51306195, 51407178), the Anhui Provincial Natural Science Foundation under Grant No 1408085QE90, by the National Magnetic Confinement Fusion Program of China (Grant Nos. 2014GB106000, 2014GB106003, and 2014GB105002) and by the Science Foundation of Institute of Plasma Physics, Chinese Academy of Sciences (Grant No. Y45ETY2305). The views and opinions expressed herein do not necessarily reflect those of the CFETR Organization and EAST Team.

Competing interests

The authors declare that they have no competing interests.

Received: 6 June 2016 Accepted: 18 November 2016

Published online: 01 December 2016

\section{References}

Bottura L (1996) A numerical model for the simulation of quench in the ITER magnets. J Comput Phys 125:26-41 Bottura L (2000) A practical fit for the critical surface of NbTi. IEEE Trans Appl Supercond 10:1054-1057

Bruzzone P et al (2006) A critical review of coupling loss results for cable-in-conduit conductors. IEEE Trans Appl Supercond $16: 827-830$

Bruzzone P et al (2009) Test results of a Nb 3 Sn cable-in-conduit conductor with variable pitch sequence. IEEE Trans Appl Supercond 19:1448-1451

Cau F, Bruzzone P (2010) Dependence of the AC loss on the aspect ratio in a cable in conduit conductor. Supercond Sci Technol 23:045011

Cau F et al (2009) AC loss measurements in CICC with different aspect ratio. IEEE Trans Appl Supercond 19:2383-2386

Gaio E et al (2013) Full scale prototype of the JT-60SA quench protection circuits. Fusion Eng Des 88:563-567 
Godeke A et al (2006) A general scaling relation for the critical current density in Nb3Sn conceptual design of model coil for the 40 Thybrid magnet superconducting outsert. Supercond Sci Technol 19:R100-R116

Hamada K et al (2002) Experimental results of pressure drop measurement in ITER CS model coil tests. Adv. Cryo. Eng. 47:407-414

Hamada K et al (2004) Effect of electromagnetic force on the pressure drop and coupling loss of a cable-in-conduit conductor. Cryogenics 44:45-52

Ilyin Y et al (2010) Performance analysis of the ITER poloidal field coil conductors. IEEE Trans Appl Supercond 20:415-418

ITER 2009 Design Description Document: DDD 11. ITER_D_2NBKXY v1.2

Jong CTJ, et al (2009) Mechanical behaviour of ITER central solenoid. In 23rd IEEE/NPSS symposium on fusion engineering

Kaminski M, Schrefler B (2000) Probabilistic effective characteristics of cables for superconducting coils. Comput Methods Appl Mech Eng 188:1-16

Lacroix B et al (2013) Quench propagation and quench detection in the TF system of JT-60SA. Fusion Eng Des 88:559-562

Martovetsky N, Radovinsky A (2006) ITER CS quench detection system and its qualification by numerical modeling. IEEE Trans Appl Supercond 24:4202104

Martovetsky N et al (2016) ITER central solenoid insert test results. IEEE Trans Appl Supcond 26:4200605

Meuris C et al (2010) Using the Vincenta code to analyse pressure increases in helium during the quench of a superconducting magnet. Cryogenics 50:177-186

Nicollet S et al (2013) Quench of ITER poloidal field coils: influence of some initiation parameters on thermo-hydraulic detection signals and main impact on cryogenic system. Cryogenics 53:86-93

Nicollet S, et al (2014) Short initial length quench on CICC of ITER TF coils. In: AIP conference proceedings vol 1573, pp 422-429

Ren Y et al (2012) Thermal-hydraulic analysis of a model coil for 40-T hybrid magnet superconducting outsert. IEEE Trans Appl Supercond 22:4900105

Ren Y et al (2015a) Electromagnetic, mechanical and thermal performance analysis of the CFETR magnet system. Nucl Fusion 55:093002

Ren Y et al (2015b) Quench simulation of the hybrid magnet superconducting outsert being built in China. J Fusion Energy 34:1146-1150

Takahashi Y et al (2005) Quench detection using pick-up coils for the ITER central solenoid. IEEE Trans Appl Supercond 15:1395-1398

TakahashiY et al (2006) Simulation of quench tests of the central solenoid insert coil in the ITER central solenoid model coil. IEEE Trans Appl Supercond 16:783-786

Wang Q, Weng P, He M (2004) Simulation of quench for the cable-in conduit conductor in HT-7U superconducting Tokamak magnets using porous medium model. Cryogenics 44:81-92

Zani L et al (2005) JC(B, T) characterization of NbTi strands used in ITER PF-relevant insert and full-scale sample. IEEE Trans Appl Supercond 15:3506-3509

\section{Submit your manuscript to a SpringerOpen ${ }^{\circ}$ journal and benefit from:}

- Convenient online submission

\section{- Rigorous peer review}

- Immediate publication on acceptance

- Open access: articles freely available online

- High visibility within the field

- Retaining the copyright to your article

Submit your next manuscript at $\boldsymbol{\nabla}$ springeropen.com 